\title{
Malignant lymphoma occurring in the residual stomach following gastrectomy: plus discussion based on the literature in Japan
}

\author{
Hiroo Oshita $^{1}$, Hiromi Tanemura ${ }^{1}$, Akihiro Kanno ${ }^{2}$, Mitsuhiko Kusakabe ${ }^{1}$, Tsuneaki Hato ${ }^{1}$, Eitchi Tomita ${ }^{2}$, \\ and Tetsuya Yamada ${ }^{3}$ \\ ${ }^{1}$ Department of Surgery, Gifu Municipal Hospital, 7-1 Kashimacho, Gifu 500-8323, Japan \\ ${ }^{2}$ Department of Gastroenterology Medicine, Gifu Municipal Hospital, Gifu, Japan \\ ${ }^{3}$ Department of Clinical Laboratory, Gifu Municipal Hospital, Gifu, Japan
}

\begin{abstract}
Malignant lymphoma of the remnant stomach was diagnosed in a 53-year-old man 8 years after gastrectomy for a perforated gastric ulcer. Endoscopic examination demonstrated protruding lesions spreading over the entire residual stomach, and biopsy revealed malignant lymphoma. Rectal cancer was diagnosed simultaneously. The residual stomach was completely excised, with splenectomy, in parallel with low anterior resection of the rectum. Histological studies revealed that the lesion in the residual stomach was a lymphoma of the diffuse, large-cell type, according to the Lymphoma-Leukemia Study Group (LSG) classification, with positivity for CD20 and CD45RA, leading to a diagnosis of B-cell lymphoma. Helicobacter pylori microorganisms were found on the luminal surface of the tumor. Despite postoperative chemotherapy, the patient died of disseminated lymphoma 34 months later. Although malignant lymphoma occurring in the residual stomach following gastrectomy is rare, particular attention should be given to the possible presence of a malignant tumor when examining the residual stomach following gastrectomy.
\end{abstract}

Key words Malignant lymphoma $\cdot$ Residual stomach

\section{Introduction}

Residual stomach cancer is known to be one of the delayed complications following gastrectomy. However, malignant lymphoma of the residual stomach is extremely rare. We report a case of residual stomach malignant lymphoma after gastrectomy for a perforated gastric ulcer, and discuss other reported cases in Japan.

Offprint requests to: $\mathrm{H}$. Oshita

Received: April 3, 2002 / Accepted: November 28, 2002

\section{Case report}

A 53-year-old man was examined because of mild anemia (hemoglobin [Hb], 11.6g/dl) in August 1996. He had undergone pyloric gastrectomy with Billroth-I reconstruction for perforated benign gastric ulcer in 1988. Gastric transillumination and endoscopy showed comparatively soft, giant fold-like protruding lesions spreading over the entire residual stomach, and biopsy revealed the lesions to be malignant lymphoma. X-Rays of the large intestine and colonoscopy with biopsy demonstrated Borrmann type 2 highly differentiated adenocarcinoma in the upper rectum. At laparotomy in November 1996, a tumor was observed throughout the residual stomach. Lymph nodes were enlarged around the stomach and along the common hepatic artery and splenic artery and in the hepatoduodenal ligament. Total gastrectomy with splenectomy and purging of the lymph nodes was performed, in addition to a lower anterior resection of the rectum for the rectal cancer. The surgical specimen, which consisted of a $12 \times 9-\mathrm{cm}$ gastric stump, showed giant fold-like protruding lesions occupying the entire residual stomach (Fig. 1). Histological examinations revealed large lymphocyte-like cells with a round or cleaved nucleus infiltrating across the proper muscle layer from the mucous membrane of the stomach wall. Similar cellular infiltration was also observed for lymph nodes nos. 1, 2, 3, 4sb, 8a, 10, 11,12 , and 272 (lymph nodes along the iliac artery). According to the results of immunohistological studies, the tumor was positive for B-cell markers, i.e., CD20 and CD45RA, and negative for T-cell markers, i.e., CD3 and CD45RO. In addition, both heavy-chain immunoglobulin IgM and light-chain $\kappa$ were strongly and monoclonally positive. These features were diagnostic of B-cell lymphoma of the diffuse, large-cell type. Helicobacter pylori microorganisms were demonstrated at the luminal surface of the tumor. The histology of the rectal cancer was highly differentiated adenocarcinoma 


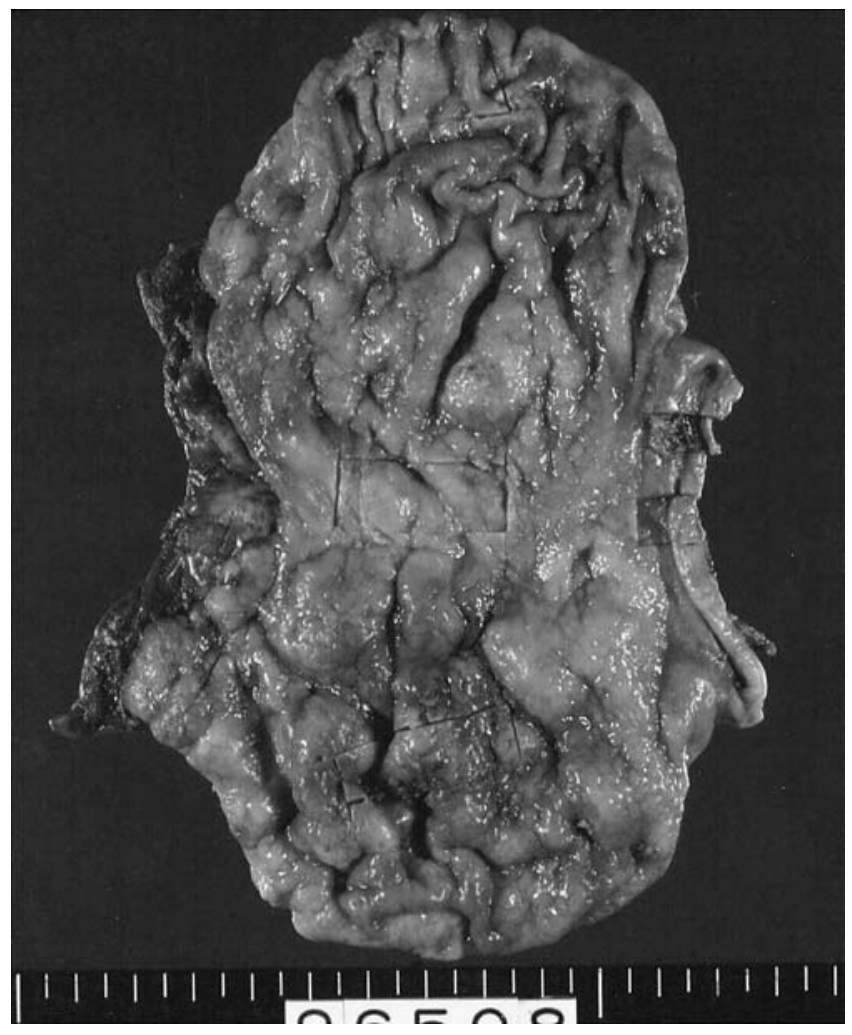

Fig. 1. Macroscopic view of excised stomach specimen. Photograph shows giant fold-like protuding lesion, measuring $12 \times 9 \mathrm{~cm}$, occupying the entire residual stomach

that had infiltrated to the subserous layer, and lymph node metastasis was not observed. Despite postoperative chemotherapy, including the CHOP regimen (Cyclophosphamide [CPA], Doxorubicin [ADR], Vincristine [VCR], and Predonisolone [Pre]) and others, the lymphoma recurred in the patient's head and neck region, abdomen, and thorax, and he died 34 months after the surgery.

\section{Discussion}

Many of the malignant tumors which occur in the residual stomach are cancers, although malignant lymphomas are extremely rare. Overseas, 15 cases have been tabulated and reported by Sebagh et al. [1] and 8 cases by Vanbockrijck et al. [2]. In Japan, only 27 cases have been reported in the literature, since an autopsy case was reported by Yamagiwa [3] in 1972.

De Boer et al. [4] defined residual stomach cancer as a cancer which occurred at least 5 years after the initial surgery performed for a benign disease of the stomach or duodenum. In addition, there are some relapsed cases in the residual stomach, because gastric malignant lymphoma is frequently multifocal [5]. Therefore, in order to determine the characteristics of malignant lymphoma occurring in the residual stomach following gastrectomy, it is important to exclude the cases in which the initial nidus was malignant lymphoma. In this view, in Japan, there were 18 reported cases, including our own case, in which malignant lymphomas occurred in the residual stomach at least 5 years after gastrectomy (Table 1) [3,6-20].

Most of the initial diseases leading to gastrectomy were benign diseases such as duodenal or gastric ulcer. The sensitivity of endoscopic biopsy to diagnose malignant lymphoma in the residual stomach was low. Gastrectomy usually involved D2 node dissection, and sometimes resection of other organs. Despite postoperative chemotherapy, few actual longterm survivors were reported, although this may be related to short follow-up periods.

There are numerous reports describing factors considered to be involved in the manifestation of residual stomach malignant tumors. Histologically, atrophic gastritis, polyps, intestinal metaplasia, and other mucous membrane changes are frequently observed in the residual stomach. Langhans et al. [21] and Ovaska et al. [22] have indicated that atrophic gastritis, which occurs due to back flow of bile and duodenal contents into the residual stomach, causes mucosal metaplasia, and that this, in turn, causes a malignant transformation. In addition, Sigal et al. [23] have suggested that lymphocyte infiltration, which occurs due to chronic inflammation and ulceration of the mucous membrane, develops into lymphoma. In some patients, the malignancy had been preceded by lymphoid proliferation or focal lymphoid hyperplasia within the stomach wall or anastomotic site [24,25]. However, it is difficult to know whether this lymphoid hyperplasia is so-called lowgrade malignant lymphoma of mucosa-associated lymphoid tissue (MALT) [1]. H. pylori infection has been considered to play an important role in the mechanism of occurrence of gastric malignant lymphoma [26]. Reviews in the United States and Europe have indicated a low correlation between $H$. pylori infection and the manifestation of residual stomach malignant lymphoma [1,2]. The reason for this, however, is believed to be due to the frequent use of the Billroth-II anastomosis, in which the growth of $H$. pylori is inhibited by the back flow of bile acid. However, $H$. pylori infection was verified in our patient and in the patient reported by Kondo et al. [19], both of whom had a Billroth-I anastomosis, which is minimally affected by bile acid. Therefore, $H$. pylori infection might be one of the causes of the residual stomach malignant lymphoma, rather than bile acid back flow, in these patients. It is thus interesting to note that the cause of residual stomach malignant lymphoma may vary depending on the method of anastomosis employed following gastrectomy. 


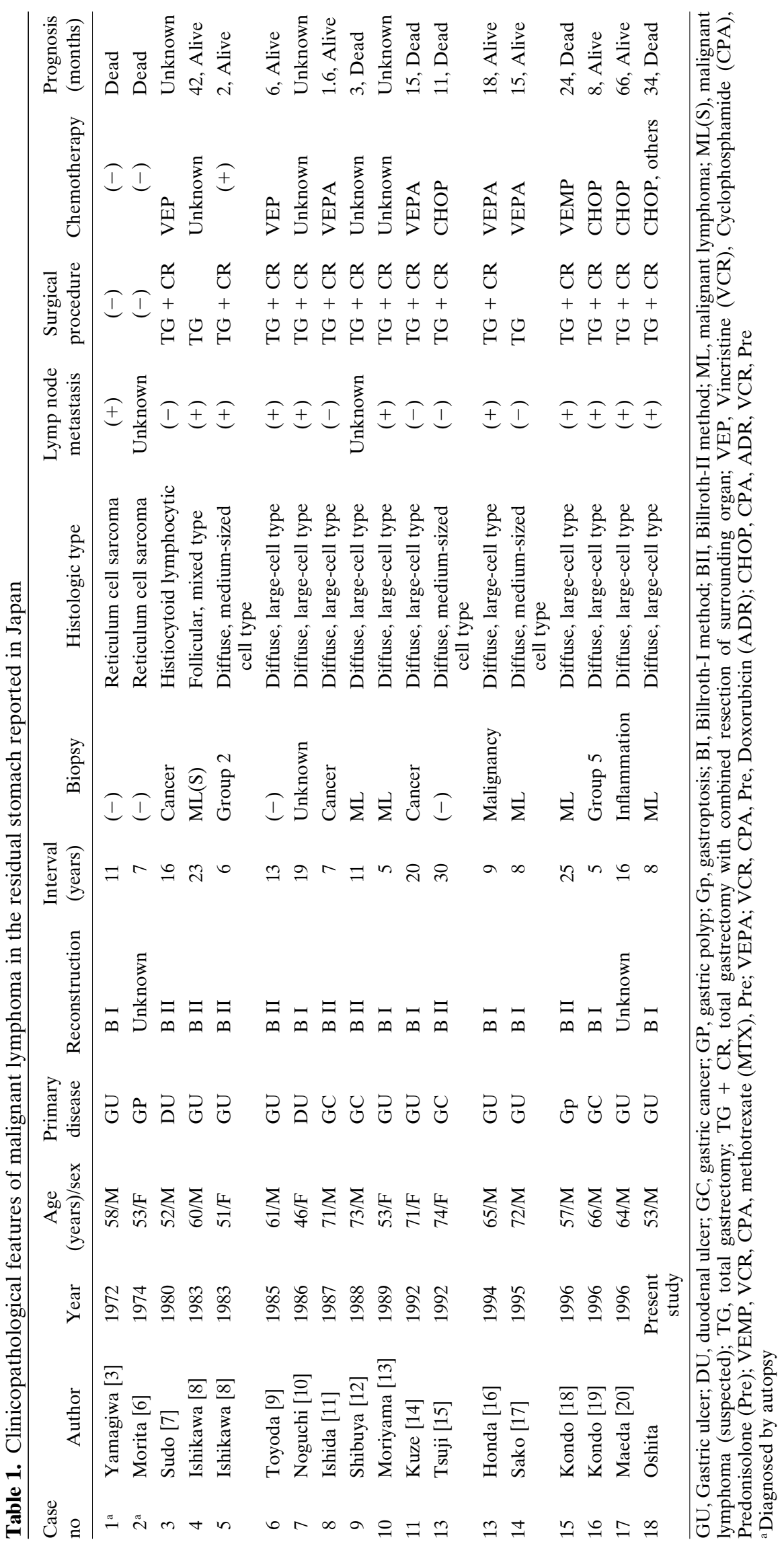


In conclusion, malignant lymphoma occurring in the residual stomach is a rare disease which is difficult to diagnose by endoscopy. Therefore, adequate attention should be given to the potential occurrence of malignant lymphoma when examining the residual stomach following gastrectomy.

\section{References}

1. Sebagh M, Flejou JF, Potet F. Lymphoma of the gastric stump. J Clin Gastroenterol 1995;20:147-50.

2. Vanbockrijck M, Pierre E, Willems G, Kloppel G. Primary nonHodgkin lymphoma of the gastric stump. Pathol Res Pract 1995; 191:525-9.

3. Yamagiwa $\mathrm{H}$. Two cases of malignant tumor in residual stomach. Internal Medicine 1972;29:352-6.

4. De Boer J, Huibregtse K, Tytgat GN. Gastric carcinoma after partial gastrectomy. Tidschr Gastroenterol 1978;3:157-66.

5. Sano T, Katai H, Sasako M, Maruyama K. Treatment strategy for primary gastric lymphoma. Gastroenterol Surg 1996;19:63-7.

6. Morita T, Masuda T, Nakamura S, Imada T, Enzan H, Kohama Y. Two cases of malignant tumor of the stomach after partial gastrectomy. Hiroshima Igaku (Hiroshima J Med Sci) 1974;27:1197-200.

7. Sudo T, Shirahane M, Kawamura M, Chin S, Umemura H, Hisayama K, et al. A case of malignant lymphoma in the remnant stomach after gastrectomy. J Clin Surg 1980;35:1769-72.

8. Ishikawa Y, Aioi H, Matsumoto M, Yamamura T, Kusunoki T, Ito N. Clinical study of sarcomas of the remnant stomach. J Jpn Soc Clin Surg 1983;44:222-30.

9. Toyoda T, Tsuruta K, Nakajima A, Habu H, Hoshi K, Saitou S, et al. A case of malignant lymphoma of the remnant stomach. Gastroenterol Surg 1985;8:495-9.

10. Noguchi Y, Imada T, Amano T, Abe S, Yamamoto Y, Tamura S, et al. A case of malignant lymphoma of the remnant stomach. Jpn J Cancer Clin 1986;32:543-50.

11. Ishida N, Yoshimine S, Tomida T, Kita T, Hidaka N. An operative case of malignant lymphoma in the residual stomach after gastrectomy for gastric carcinoma. Jpn J Gastroenterol Surg 1987; 20:804-7.

12. Shibuya H, Furuya T, Nishida R, Fujisawa Y, Hata F, Nakajima Y. A case of malignant lymphoma of remnant stomach. Jpn J Gastroenterol Surg 1988;21:123-6.

13. Moriyama Y, Nagasawa M, Nakayama H, Jinbou S, Morioka M, Sasaki T, et al. A case of B-cell type primary malignant lymphoma developed in the gastric remnant. Prog Dig Endosc 1989;35: 260-3.

14. Kuze M, Umeda, H, Shimamura S, Sanda M, Yoshimura A, Hidaka N. An operative case of malignant lymphoma in the remnant stomach after gastrectomy for gastric ulcer. J Jpn Soc Clin Surg 1992;53:1347-51.

15. Tsuji F, Kimura F, Yamazaki Y, Yamanaka Y, Yamamoto M. A case of malignant lymphoma in the residual stomach. Jpn J Gastroenterol Surg 1992;25:2968-72.

16. Honda K, Watanabe F, Nomizu T, Yamaki Y, Tsuchiya A, Abe R. Non-Hodgkin's lymphoma of the gastric stump developing 9 years after a distal gastrectomy for a peptic ulcer: a case report and review of the literature. Jpn J Surg 1994;24: 815-8.

17. Sako S, Okajima K, Isozaki H, Nakata E, Ryo H, Ishibashi T, et al. A case of malignant lymphoma in the residual stomach. J Jpn Soc Clin Surg 1995;56:1838-44.

18. Kondo K, Yokoyama Y, Yokoyama I, Kikuchi M, Kuno Y, Kataoka M, et al. Malignant lymphoma of the gastric stump developing 25 years after a distal gastrectomy for benign gastric disease: report of a case. Jpn J Surg 1996;26:803-6.

19. Kondo R, Watanabe $H$, Kumeda $S$, Iwasa $T$, Nakazawa I, Shigematsu S. A case of malignant lymphoma in the residual stomach after gastrectomy for gastric carcinoma. Endosc Forum Dig Dis 1996;12:226-31.

20. Maeda A, Yamaguchi A, Isogai M, Hori A, Kin Y, Mori N. A case of malignant lymphoma in the remnant stomach. Surgery 1996; 58:515-8.

21. Langhans P, Heger RA, Hohenstein J, Schlake W, Bunte H. Operation-sequel carcinoma of the stomach: experimental studies of surgical techniques with or without resection. World J Surg 1981;5:595-605.

22. Ovaska JT, Havia TV, Kujari HP. Retrospective analysis of gastric stump carcinoma patients treated during 1946-1981. Acta Chir Scand 1986;152:199-204.

23. Sigal SH, Saul SH, Auerbach HE, Raffensperger E, Kant JA, Brooks JJ. Gastric small lymphocytic proliferation with immunoglobulin gene rearrangement in pseudolymphoma versus lymphoma. Gastroenterology 1989;97:195-201.

24. Libson E, Dravid VS, Wechsler RJ, Bloom RA. Gastric stump lymphoma. Leuk Lymphoma 1994;15:357-60.

25. Wolf JA Jr, Spjut HJ. Focal lymphoid hyperplasia of the stomach preceding gastric lymphoma. Case report and review of the literature. Cancer 1981;48:2518-23.

26. Wotherspoon AC, Ortiz-Hidalgo C, Falzon MR, Isaacson PG. Helicobacter pylori-associated gastritis and primary B-cell gastric lymphoma. Lancet 1991;338:1175-6. 